\title{
Novel poly herbal muco-adhesive formulation for treatment of oral aphthous ulcer
}

\author{
Rimjhim Sahu ${ }^{1}$, Deepika Jain ${ }^{2}$, Rekha Mehani ${ }^{1 *}$, Hemani ${ }^{3}$, Lal Hingorani ${ }^{3}$, Vijay Thawani ${ }^{1}$
}

${ }^{1}$ Department of Pharmacology, PCMS and RC Bhopal, Madhya Pradesh, India

${ }^{2}$ Department of Community, Dentistry RAU College of Dentistry, Indore, Madhya Pradesh, India

${ }^{3}$ Pharmanza Herbals Pvt. Ltd., Gujarat, India

Received: 22 June 2021

Revised: 07 July 2021

Accepted: 08 July 2021

*Correspondence:

Dr. Rekha Mehani,

Email: drrekhasanjay@gmail.com

Copyright: $($ ) the author(s), publisher and licensee Medip Academy. This is an open-access article distributed under the terms of the Creative Commons Attribution Non-Commercial License, which permits unrestricted non-commercial use, distribution, and reproduction in any medium, provided the original work is properly cited.

\begin{abstract}
Background: Oral ulcers are the most frequent lesions that cause discomfort for which the patients seek treatment for alleviating pain and facilitate early healing. Various treatment modalities from modern medicine and Ayurveda are used in the form of ointments and mouthwashes with varying efficacy. Anti-inflammatory medicines, enzymatic preparations, gamma globulins and immune suppressants have been used.

Methods: Extracts of five chosen herbs, Glycyrrhiza glabra, Acacia catechu, Punica Granatum, Curcuma longa and Mentha piperita were used for preparing mucoadhesive gel for the treatment of oral aphthous ulcers of any etiology. Gel was prepared by cold method of Schmolka at M/s Pharmanza Herbals Pvt. Ltd., India. Five formulations were prepared with using different concentration of active pharmaceutical ingredient (API) extracts.

Results: Formulations were analyzed for different physical and chemical properties. Preliminary trial was done with five formulations. The F5 formulation has the premier viscosity because of its higher polymer content; it is able to remain on mucous surface long enough to release its API effect. Since the uniformity, proper appearance, stability and acceptable viscosity and gel strength the F1 formulation was selected as the superior formulation which could prove ideal for treatment of oral aphthous ulcers.

Conclusions: The results provide strong evidence that polyherbal gel containing extracts of Glycyrrhiza glabra, Acacia catechu, Punica granatum, Curcuma longa and Mentha piperita on the basis of their analgesic, anti-inflammatory, antioxidant, wound healing, antimicrobial and local anesthetic properties can be used as an effective and safe alternative for the management of aphthous ulcers.
\end{abstract}

Keywords: Antiulcer, Analgesic, Glycyrrhiza glabra, Acacia catechu, Punica Granatum, Curcuma longa

\section{INTRODUCTION}

\section{Aphthous ulcer}

An oral ulcer which occurs on the mucous membrane of the oral cavity is called aphthous ulcer, or canker sore. Aphthous ulcer, is a common condition affecting oral mucosa, and has the property of self-healing. ${ }^{1}$ It is a known fact that oral aphthous ulcers affect between 5 to $25 \%$ of population of any age group. The main types of oral ulcers are minor ulcers. These are around 2-8 $\mathrm{mm}$ in diameter and usually clear up in 10 to 15 days. Major ulcers are bigger and deeper, often with a raised or irregular border. These can take several weeks to heal and may leave a scar in the mouth. 


\section{Treatment of oral aphthous ulcers}

Many therapies have been recommended to treat oral ulcers which aim to decrease the symptoms of pain and duration of ulcers., ${ }^{2,3}$ Antiseptics and anti-inflammatory medicines are considered to be the first line of treatment for aphthous ulcer. Topical antibiotics, topical corticosteroids are used in gel or rinse form. ${ }^{4,5}$

\section{Mucoadhesive drug delivery system}

Mucoadhesive medicine delivery can be defined as absorption of medicine via the mucous membranes of the oral cavity. It is a relatively new drug delivery system which was first introduced in 1980's for delivering the medicine in controlled manner and providing the ease of controlled medicine delivery.

Bioadhesion is commonly defined as the adhesion between two materials, at least one of which is biologic in nature that are held together by means of interfacial forces. Mucoadhesive medicine delivery systems utilize this property and have been developed for oral, nasal, vaginal and rectal routes for systemic and local effects.

Mucoadhesive medicine delivery system remains in close contact with the absorption surface- the mucous membrane, releasing the medicine at the action site leading to better bioavailability and subsequent local and systemic effects. The potential use of mucoadhesive systems as medicine carriers lies in its prolongation of the adherence time at the absorption site, allowing intensified contact with the epithelial barrier. ${ }^{6}$

The efficacy of bioadhesive hydrogel patches, made up of a pharmaceutical grade cellulose derivative aid in the healing and controlling the pain caused by aphthous ulceration. $^{7}$

Many medicinal plants and dietary nutrients have been shown to possess antiulcer activities tulsi, neem, curcumin, liquorice, pomegranate, Acacia catechu, Mentha piperita and ginger are considered as home remedies in many parts of the country. ${ }^{8}$
The use of herbal products in the treatment of oral aphthous ulcer can provide safety in contrast to the synthetic topical steroids. We intended to develop semisolid muco-adhesive dosage form of polyherbal ingredients for potential treatment of aphthous ulcer. Other reasons for this study are their low cost, safety, better tolerability and improved efficacy.

\section{Aim}

Aim of the study was to formulate a poly herbal mucoadhesive gel which can provide effective treatment for oral aphthous ulcers decreasing the healing time following patch therapy, and to assess pharmaceutical parameters of the formulation by in vitro analysis.

\section{METHODS}

After a thorough systematic scientific review of literature five herbal extracts were identified and selected on the basis of their documented analgesic, anti-inflammatory, antioxidant, wound healing, antimicrobial and local anesthetic properties on various parameters of oral ulcers. The herbal ingredients used are shown in Table 1.

\section{Equipment and instruments used}

The following equipments and instruments were used: digital balance, $\mathrm{pH}$ meter, magnetic stirrer, digital water bath, ultra sonicator, Brookfield LVDV-II and pro viscometer, Shimadzu UV 1800 spectrophotometer and high performance liquid chromatography (HPLC).

\section{Preparation of gel formulation}

After obtaining clearance from institutional ethics committee vide letter no. IEC-2017/05 the Glycyrrhiza glabra extract, pomegranate extract, Mentha piperita extract, Catechu extract, and Curcumin longa extract were procured from M/s Pharmanza Herbals Pvt. Ltd., India. All other reagents and chemicals were locally procured in analytical grade. Method of gel formulation and in vitro evaluation of gel were done with appropriate method. ${ }^{9}$

Table 1: The herbs used and their documented uses.

\begin{tabular}{|c|c|c|c|c|}
\hline Name & Scientific name & Parts used & Chemical ingredient & Properties \\
\hline Liquorice & $\begin{array}{l}\text { Glycyrrhiza } \\
\text { glabra }\end{array}$ & Roots, rhizomes & Glycoside glycyrrhizin & $\begin{array}{l}\text { Demulcent, anti-inflammatory, } \\
\text { antiulcer }\end{array}$ \\
\hline Catechu & Acacia catechu & $\begin{array}{l}\text { Dried bark } \\
\text { heartwood }\end{array}$ & Tannin flavonoids & $\begin{array}{l}\text { Anti-bacterial, astringent and } \\
\text { antiulcer }\end{array}$ \\
\hline Pomegranate & $\begin{array}{l}\text { Punica } \\
\text { granatum }\end{array}$ & $\begin{array}{l}\text { Fruit and its } \\
\text { skin }\end{array}$ & Phenolics, flavonoids & $\begin{array}{l}\text { Anti-inflammatory, antibacterial, } \\
\text { antifungal, antioxidant and antiulcer }\end{array}$ \\
\hline Turmeric & Curcuma longa & $\begin{array}{l}\text { Roots and } \\
\text { rhizomes }\end{array}$ & Curcumin & $\begin{array}{l}\text { Antioxidant, anti-inflammatory, } \\
\text { analgesic, anti-fungal }\end{array}$ \\
\hline Peppermint & Mentha piperita & Leaves & $\begin{array}{l}\text { Essential oils like } \\
\text { menthol }\end{array}$ & $\begin{array}{l}\text { Anti-inflammatory, anesthetic, } \\
\text { fungicidal }\end{array}$ \\
\hline
\end{tabular}



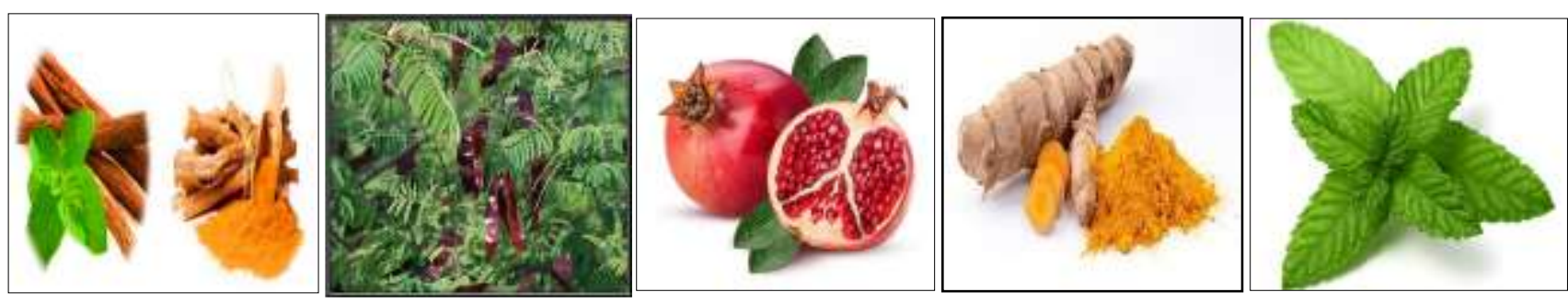

Figure 1: Glycyrrhiza glabra, Acacia catechu, Punica Granatum, Curcuma longa and Mentha piperita.

Table 2: Ingredients and their concentrations used in the five gel formulations.

\begin{tabular}{|llllll|}
\hline Ingredient & F1 & F2 & F3 & F4 & F5 \\
\hline Curcuma extract (mg) & 10 & 500 & 500 & 10 & 10 \\
\hline Glycyrrhiza extract (mg) & 8 & 800 & 800 & 8 & 8 \\
\hline Punica extract (mg) & 10 & 500 & 500 & 10 & 10 \\
\hline Acacia extract (mg) & 5 & 500 & 500 & 5 & 5 \\
\hline Menthe oil (mg) & 2 & 200 & - & 2 & 2 \\
\hline 2 mg HPMC E 50 (\%) & 3 & 2 & - & 3 & 1 \\
\hline Carbopol 934 P (\%) & 1 & 1 & 1 & 1 & 0.15 \\
\hline Sodium benzoate (\%) & 0.15 & 0.15 & 0.15 & 0.15 & 10 \\
\hline Propylene glycol (\%) & 10 & 10 & 13 & 10 & 30 \\
\hline Water (\%) & 50 & 10 & $100 \mathrm{ml}$ & 20 & 40 \\
\hline Ethanol (\%) & 40 & 10 & - & 30 & - \\
\hline
\end{tabular}

Gel was prepared by cold method of Schmolka at M/s Pharmanza Herbals Pvt. Ltd., India. Carbopol 934 was accurately weighed in a beaker and dispersed in distilled water till the carbopol swelled. After swelling of carbopol, hydroxypropylmethylcellulose (HPMC) E 50 was added and stirred using mechanical/lab stirrer at $1000 \mathrm{rpm}$ for 30 $40 \mathrm{~m}$. In another beaker ethanol was taken in required quantity of extracts. Propylene glycol was added in the required quantity. Then preservatives were added along with menthe oil with constant stirring at $1200 \mathrm{rpm}$. In beaker containing Carbopol the ethanol mixed extracts were transferred and with constant stirring at $1200 \mathrm{rpm}$.

Finally, water was added for making up the volume. Once the formation of the gel was completed it was packed in airtight container and stored in refrigerator.

\section{RESULTS}

Five formulation were prepared by using ingredients at different concentration and in-vitro analysis of formulation was done for: $\mathrm{pH}$, viscosity, spreadibility, gel strength, muco adhesive strength, and microbial activity.

Preliminary trial was done with five formulations. The F1 formulation has the premier viscosity because of its higher polymer content; it is able to remain on mucous surface long enough to release the effect of its active ingredients. Because of uniformity, proper appearance, stability and acceptable viscosity F1 formulation was selected as the superior formulation for the treatment of oral aphthous ulcers.

\section{Other parameters studied}

$p H$

1 gram of formulation was dispersed in $100 \mathrm{ml}$ purified water and measured through $\mathrm{pH}$ meter. ${ }^{8,10,11}$

\section{Viscosity}

Viscosity was measured by Brookfield (DV-III) viscometer. Gel was poured into the container and the proper spindle was attached. Then the viscosity was measured at $25^{\circ} \mathrm{C}$ at $50-250 \mathrm{rpm} .{ }^{8,10,11}$

\section{Spreadibility}

For the determination of spreadibility, excess of sample was applied between two glass slides and was compressed to uniform thickness by placing $10 \mathrm{gm}$ weight for $5 \mathrm{~m}$. The time required to separate the two slides, i.e. the time in which the upper glass slide moves over the lower, was taken as measure of spreadibility. $8,10,11$

\section{Mucoadhesive strength}

The tensiometer (Fisher) was calibrated and then the gel brought in contact with sodium alginate (substitute for mucin) for $5 \mathrm{~m}$. Then the required force to detach the gel from solution surface (speed of $0.2 \mathrm{inch} / \mathrm{min}$ ) was determined in dyne $/ \mathrm{cm}^{2} \cdot 12,13$

Drug release by HPLC method and microbial count by USP $<2021>$ method was done for formulation F1. 
Preliminary trial was done with five formulations. The F5 formulation has the premier viscosity because of its higher polymer content; it is able to remain on mucous surface long enough to release its API effect. Since the uniformity, proper appearance, stability and acceptable viscosity and gel strength the F1 formulation was selected as the superior formulation which could prove ideal for treatment of oral aphthous ulcers.

Table 3: Physical parameters of the formulation.

\begin{tabular}{|llllll|}
\hline Parameter & F1 & F2 & F3 & F4 & F5 \\
\hline Clarity & Clear & Turbid & Opaque & Opaque & Opaque \\
\hline Colour & Yellowish brown & Dark yellow & Yellow & Yellow & Yellow \\
\hline Homogeneity & ++++ & +++ & ++ & +++ & +++ \\
\hline Particulate matter & Not present & Present & Present & Present & Present \\
\hline Consistency & \multirow{2}{*}{ Smooth } & Coarse & Lumps & Spreadibility & Gel formed but viscosity \\
& & & formed & was not proper & was not in range \\
\hline
\end{tabular}

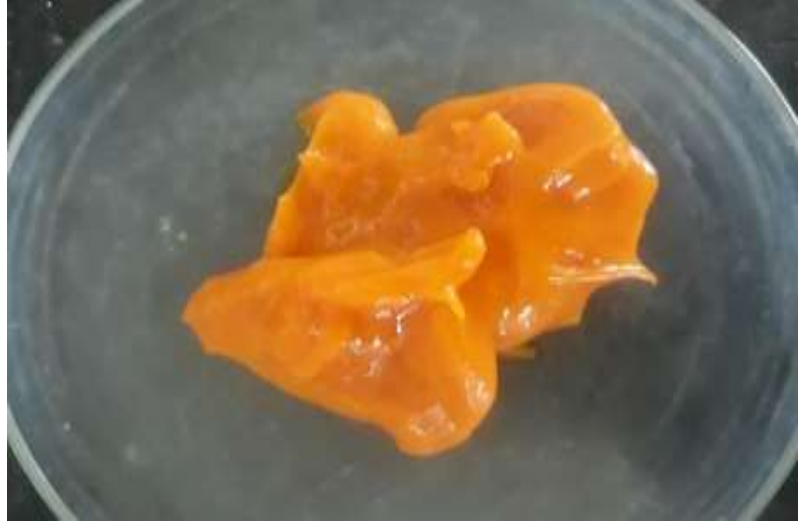

Figure 3: Polyherbal mucoadhesive gel.

Table 4: Other parameters of gel analysis of F1 formulation.

\begin{tabular}{|ll|}
\hline Parameter & Range \\
\hline pH & 6.8 \\
\hline Viscosity (cps) & $5607 \pm 154$ \\
\hline Spreadibility (sec) & 10 \\
\hline Mucoadhesive strength (dyne/cm ${ }^{2}$ ) & 24.3 \\
\hline Drug release (\%) & \\
\hline Curcuminoids & 0.59 \\
\hline Punicalagin & 0.1 \\
\hline Glycyrrhetinic acid & 0.14 \\
\hline Microbial count (total plate count) & $<10$ \\
\hline Yeast and mold & \\
\hline Escherichia coli & \\
\hline Salmonella & All absent \\
\hline S. Aureus & \\
\hline Enterobacteriaceae & \\
\hline
\end{tabular}

\section{DISCUSSION}

In the recent past herbal treatments have gained popularity for the oral lesions. ${ }^{8}$ Extracts of herbal plants like aloe, Terminalia chebula, Vetiveria zizanioides, ginseng, capsicum have been used successfully for the treatment of aphthous ulcers. Alambayan et al concluded that aqueous extract acacia catechu wild displayed antiulcer activity. ${ }^{14}$ Some other studies have also mentioned about the role of herbal plants in treatment of ulcers in cancer patients. Najafi et al showed that aqueous extract of glycyrrhiza can be effective in decreasing the severity of oral mucositis in head and neck cancer patients undergoing radiotherapy. ${ }^{15}$ Gupta et al recommended the potential use of licorice as antitubercular agent through systemic experiments and sophisticated anti-TB assay. ${ }^{16}$

The Glycyrrhiza glabra contains more than 20 triterpenoids and nearly 300 flavonoids. These contents render the glycyrrhiza glabra properties such as antimicrobial, anti-inflammatory, etc. ${ }^{17}$ Hasan et al studied effectiveness of mouthwash containing Glycyrrhiza glabra in the treatment of stomatitis oral ulcer and found that the application of glycyrrhiza glabra root extract to stomatitis mouth ulcers can reduce ulcer size and speed healing. ${ }^{18}$ Acacia catechu has anodyne, astringent, bactericide, refrigerant, stimulant, and styptic properties. ${ }^{19}$

In the present study the herbal extract was prepared as a mucoadhesive gel formulation. Mucoadhesive gel has the ease of application, good distribution and ability of adhesion and remaining on oral mucosa for a long enough time to release its drug, Aslani et al reported this fact in their study which stated that this formulation can be well accepted for treatment of oral ulcers and diseases such as aphthous. $^{20}$

\section{CONCLUSION}

This study was intended to develop a semisolid mucoadhesive dosage form of polyherbal Ingredients. Herbal medicines utilize the body's natural healing process for treating conditions. For this reason, five herbal extracts were identified on the basis of their suggested analgesic, anti-inflammatory, antioxidant, wound healing, antimicrobial and local anesthetic properties. These were extracts of Glycyrrhiza glabra, Acacia catechu, Punica granatum, Curcuma longa and Mentha piperita. In our study the five afore mentioned plant extracts showed good antimicrobial activity.

The results provide strong evidence that polyherbal gel containing Glycyrrhiza glabra extract, Acacia catechu extract, Punica granatum extract, Curcuma longa extract 
and Mentha piperita extract can be used as an effective and safe alternative for the treatment of aphthous ulcers.

Future in vivo clinical studies are necessary for examining the role of this topical herbal preparation in the management of oral aphthous ulcers.

Funding: No funding sources

Conflict of interest: None declared

Ethical approval: The study was approved by the Institutional Ethics Committee

\section{REFERENCES}

1. Wray D. Aphthous ulceration. J R Soc Med. 1984;77(1): 1-3.

2. Scully C, Porter S. Oral mucosal disease: recurrent aphthous stomatitis. $\mathrm{Br} \mathrm{J}$ Oral Maxillofac Surg. 2008;46:198-206.

3. Irene BG, Yolanda JS, Ariadna CL. Treatment of recurrent aphthous stomatitis. A literature review. J Clin Exp Dent. 2014;6:168-74.

4. Baccaglini L, Lalla RV, Bruce AJ, Sartori-Valinotti JC, Latortue MC, Carrozzo M, et al. Urban legends: recurrent aphthous stomatitis. Oral Dis. 2011;17:75570 .

5. Quijano D, Rodríguez M. Topical corticosteroids in recurrent aphthous stomatitis. Systematic review. Acta Otorrinolaringol Esp. 2008;59(6):298-307.

6. Reddy PC, Chaitanya KS, Rao YM. A review on bioadhesive buccal drug delivery systems: current status of formulation and evaluation methods. DARU J Pharm Sci. 2011;19:385-403.

7. Mahdi AB, Coulter WA, Woolfson AD, Lamey PJ. Efficacy of bioadhesive patches in the treatment of recurrent aphthous stomatitis. J of Oral Pathol Med. 1996;25(8):416-9.

8. Teresa A, Krishnakumar K, Kumar BD, John A. Herbal Remedies For Mouth Ulcer: A Review. J Bio Innov. 2017;6(4):521-7.

9. Hau KH. Atlantic Biomed Corporation, assignee. Lesion-directed dry dosage forms of antibacterial agents for the treatment of acute mucosal infections of the oral cavity. United States patent US 6,248,718. 2001.

10. Gulzar A. Preliminary phytochemical and antimicrobial screening of leaves extract of Acacia catechu Willd, J Pharm Res. 2010;3(11):2583-4.
11. Devi VG, John A, Devi RS, Prabhakaran VA. Pharmacognostical studies on Acacia catechu Willd and identification of antioxidant principles. Int $\mathrm{J}$ Pharm Pharm Sci. 2011;3:108-11.

12. Chauhan I, Sharma A, Gangwar M, Gautam M, Singh A, Goel R, et al. Gastric antiulcer and ulcer healing effects of punica granatum peel extract in rats: role of offensive and defensive mucosal factors and oxidative stress. Int J Pharm Sci. 2017;9(5):6-11.

13. Goyal R, Thawani V, Nagtilak S, Pathania M, Jindal S. Antioxidative effect of Punica granatum (pomegranate) on biochemical parameters in patients with diabetes mellitus (type 2) and myocardial infarction. Int J Adv Res. 2016;4(5):857-64.

14. Geetha RV, Roy A. In Vitro Evaluation of Antibacterial Activity Three Herbal Extracts on Methicillin Resistant Staphylococcus aureus [MRSA]. J Pharm Sci Res. 2013;5(10):207-9.

15. Najafi S, Koujan SE, Manifar S, Kharazifard MJ, Kidi S, Hajheidary S. Preventive Effect of Glycyrrhiza Glabra Extract on Oral Mucositis in Patients. J Dent (Tehran). 2017;14(5):267-74.

16. Das D, Agarwal SK, Chandola HM. Protective effect of Yashtimadhu (Glycyrrhiza glabra) against side effects of radiation/chemotherapy in head and neck malignancies. Ayu. 2011;32(2):196-9.

17. Thakur A K, Raj P. Pharmacological Perspective of Glycyrrhiza glabra Linn: a Mini-Review. J Anal Pharm Res. 2017;5(5):00156.

18. Under Head and Neck Radiotherapy: A Randomized Clinical Trial. J Dent. 2017;14(5):267-74.

19. Gupta VK , Fatima A, Faridi U, Negi AS, Karuna Shanker K, Kumar JK, et al. Antimicrobial potential of Glycyrrhiza glabra roots. J Ethnopharmacol. 2008;116(2):377-80.

20. Ullah N, Khan MA, Khan T, Haq AA, Ahmad W. Mentha piperita in nephrotoxicity--a possible intervention to ameliorate renal derangements associated with gentamicin. Indian $\mathbf{J}$ Pharmacol. 2014;46(2):166-70.

Cite this article as: Sahu R, Jain D, Mehani R, Hemani, Hingorani L, Thawani V. Novel poly herbal muco-adhesive formulation for treatment of oral aphthous ulcer. Int J Basic Clin Pharmacol 2021;10:906-10. 